\title{
Redrawing craft: Archival sources and the mark in the work of artist Danica Maier
}

Lucy Renton, Kingston University

\begin{abstract}
'Stitch \& Peacock', the title of this recent exhibition by UK-based American artist Danica Maier, at The Collection and Usher Gallery, Lincoln, alludes equally to the craft, the imagery and the subversive messages hidden in her drawings for this show. The result of a seven month residency by Maier, the exhibition is the latest in a series of invitations to contemporary artists by curator Ashley Gallant to respond to objects held in the archives, as a means of presenting new perspectives on historic artefacts. Maier chose a Jacobean crewel work bedspread and a range of sixteenth- and seventeenth-century samplers, and by making work in response to these fragile objects, develops a dialogue that allows her to repeat and refract the textiles through the lens of drawing, and to make critical comparisons and equivalences between the stitch, the pixel and the drawn mark. Through her juxtapositions and reworkings, she asks us to reflect on the social context of the original female makers; to speculate on their potentially supressed frustrations, and their subversive power. Her wider drawing practice also critically invokes notions of labour, craft and technology, through her mining of a variety of archives.
\end{abstract}

\section{Keywords}

archive 
craft

drawing

line

pattern

repetition

stitch

\section{Drawing}

Danica Maier's exhibition 'Stitch \& Peacock' at The Collection and Usher Gallery, Lincoln continues an established practice playing with visual games and hidden or suppressed sexual and gendered content, through the translation of image into textile and vice versa, requiring the viewer to shift position to reveal 'dirty secrets' camouflaged within the work.

This tactic is evident in her earlier work Have Lunch Downtown (2005), a large-scale anamorphic outline drawing, created from ribbon lace tape pinned to the wall. When viewed from a specific angle these reveal images derived from pornography, in the manner of Holbein's The Ambassadors (1533) that reveals a skull when viewed from the side. The anamorphism implies two worlds that live side by side but cannot be seen concurrently. Where in Holbein this appears as a memento mori, in Maier's work, this is the hidden or suppressed sexuality of the feminine, as a 'point of view'. 
In this exhibition the size of image, or the lofty positioning of work requires the viewer to make use of the binoculars and magnifying glasses provided, to move closer and further away to fully experience the content. Her process is one of physically drawing the viewer in to draw meaning out; we are encouraged to inspect the material closely, and at a historical distance. The anamorphism here, as with Holbein's image, requires a specific viewpoint that implicates the viewer, in their recognition of the hidden, sexualized, content.

In the Lincoln works, she has replaced the stitch with the mark through a painstaking drawing process, a manifestation described in her own writings as the 'intention' of the line. The thread is a line that pierces, moving above and below the surface, always connected to, and led forward by the needle. A drawn line is set free from the pencil or pen and can retrace its steps at will, but only skim over the surface. A woven line is part of three-dimensional horizontal and vertical stacks of parallels.

Alongside an engagement with historic crafts, and focus on the physicality of the threaded line there is a more subversive political edge. Running through all these works are hidden messages. A seeming knot of lines unravels with the aid of magnifying glass or binoculars to reveal vulgar colloquial terms for female genitalia, Pigeonhole, Cono, Snatchel and Civen.

\section{Insert image (Figure 1) here}

The largest work in the show, Nest, makes full use of the high-ceilinged gallery. A huge drawing, painted directly on the wall, encloses a rarely seen Jacobean crewel work bedspread, engaging the viewer with a dizzying repetition of attenuated letters 
that mimic the outlines of the patterns in the embroidery. The curvilinear silhouette of a Tree of Life motif, with branching stems and fern-like scrolls on which perch birds, mirrored and repeated on horizontal and vertical axes in the bedspread, is enlarged through drawing to 'wallpaper' one whole side of the gallery. On closer inspection, this drawing gradually reveals a less innocent reference to fertility or ancestry; the stretched letters that make up the 'stitches' of the drawing spell out the word pigeonhole evoking the term as genital slang, linked also to the avian themes within the chosen source material. This is as ambiguous as the depiction of the birds themselves. For us, a 'pigeonhole' or 'being pigeonholed' represents a constraint that is the opposite of flight.

A selection of samplers from the archives, considered as apprentice pieces signalling an approach to the guild of womanhood, is interspersed with small, intense drawings by Maier that pick out details from the original cross-stitch embroideries (Figure 2a). Using the magnifying glass provided, which becomes an eyelet through which we espy the vulgarity beneath the prim façade, we see the lurking terms Cunt, Mutton, Mink. Does this provoke either a cheeky titter behind the hand, or a shock to the nervous sensibility? This humour or bathos of double entendre arguably still shows reverence to the original works. These are not cheap laughs, as the hidden secrets have been achieved by paying the same attention to detail, the same laborious commitment, as the original. The swear words puncture polite social interaction as the needle punctures fabric.

The labour involved in reinscribing these reminds us of female labour, of the repetition of domestic duties, and the chain of female skills handed down. From Ancient Greece, where once the woven cloth or peplos was paraded publically and 
proudly through the streets by women, the craft of needlework has been gradually transformed into the private, the patient, faithful and dutiful; the Classical myth of Penelope. Where these examples of needlecraft have come to represent rituals of the home, taste and respectability, Maier splits open the veneer of that respectability with her subterfuge.

The stitch is reframed as a precise coloured pencil mark on satin-smooth translucent paper, tracing and retracing the embroidered symbols. This Mylar ground is then mounted on aluminium plate to give a hi-tech, digital reading, reminiscent of simple early video games, and potentially pointing to a more modern pastime for young ladies. The stitch, the weave and the pixel are thus all represented through her practice of precise and methodical transcription.

Maier has selected the recurring images of birds in these samplers and set them free from their imprisoning grid of warp and weft, mounting them on individual panels to fly high on the gallery wall as a Flock (Figure $2 b$ ) requiring binoculars to view. The birds may equally represent freedom probably denied to the original makers, or allude to the kitsch interior decoration of flying ducks.

\section{Insert images (Figures 2a, 2b, 2c) here}

Happy Hunting Ground presents another bird drawn from the imagery in the samplers, this time a peacock, enlarged to huge proportions, each feather delineated in acute detail on a long billowing sheet of translucent Mylar. In one corner, a tiny deer has been extracted from its cross-stitch grid and re-imagined as a more grotesque manifestation (Figure 2c). Through increased scale, these once solid creatures are 
rendered mythic, and through the materials used in their representation disperse into a transparent dream. Constantly repeating and wilfully misinterpreting, Maier couches questions for us on what we see, what we say and what we understand.

\section{Insert image (Figure 3) here}

The last work in the show, Heirloom, does not involve drawing, but it still carries many of the themes of the other works, whilst presenting a more personal connection with the artist herself. A vitrine, once used to house a version of the Magna Carta in Lincoln Castle, is used to display heirloom quilts belonging to the artist, rolled and placed tightly together in a row. They carry connotations both of the tenderness of blanket-swaddled babies, and the reverence of sacred scrolls. These relics of ancestral female labour form a link between the artist and her own forbears' creative stitchery, a note of tenderness and pathos that complements and enhances the formal aspects and conceptual framework of the other pieces. By using the display case that formerly held the Magna Carta, a document understood as the seed of the US Constitution, Maier references her American heritage, and links back to the time of the early Pilgrims and the context for the production of samplers such as those on display here.

\section{Mining the archives: Other works}

A recent monograph Grafting Propriety: From Stitch to the Drawn Line (2015) demonstrates aspects of Maier's long-term engagement with craft archives, and her own textile collections. 


\section{Image (Figure 4) here}

Pussy Willow, a set of three drawings, was developed through Maier's involvement in an international residency organized by Bergen Academy of Art and Design, at the former Spode china factory in Stoke on Trent. These works were shown in 'Topographies of the Obsolete: Vociferous Void', as part of the 'British Ceramics Biennale'. Maier uses variations in the ubiquitous 'Willow Pattern' design as the starting point for simple short or long lines to create a new world within these drawings on Mylar. Transfers, an industrial means of applying pattern to household china, offer another kind of repetition, this time more mechanical. Maier's labour of reinventing these common transfer patterns through mark-making turns the massproduced object back into a handcrafted work of art, where the time spent making engages the viewer to spend time in their contemplation.

In all her work she asks us to look, and then to look again, to reveal other meanings in familiar objects and patterns. The final display of the three drawings that make up Pussy Willow, in three geographically separated locations (on the Spode Factory Works noticeboard and the two public noticeboards outside converted Methodist Chapels in Lincolnshire that form the 'Broadcaster' contemporary art 'venue') echoes the narrative journey of the original pattern, and forces the viewer to rely on memory to piece together the elements of the whole work.

An historical fragment from the archives of British textile designer, the late Laura Ashley, provides the starting point for the panel drawing Four Glory Holes (Figure 5).

In this work, details of a repeated image are highlighted, creating four unique 'originals', offering multiple readings that unfold as the viewer moves within the space: from printed image, to stitch, to line, to text. Four Glory Holes (Figure 5) was 
produced for an exhibition of British-based artists entitled 'Unpicked and Dismantled', part of the 'Kaunas Art Biennial: TEXTILE 07' in 2007. This showed artists whose practices interrogate concerns, agendas and methodologies that are raised by textiles, but whose outcomes use means other than the materials and processes of textiles. The exhibition was held in the National Museum of M.K. Ciurlionis, Kaunas, Lithuania and was co-curated by Danica Maier and Gerard Williams.

\section{Image (Figure 5) here}

Harlequin Slit 2010 (Figure 6) was the result of a research project and group

exhibition, 'Closely Held Secrets'. Maier worked closely with technician Tessa Acti on this piece, using embroidery machines to create the key components of the work, exploring relationships between artist and technician, in a dialogue between the visual artist and the technical agents of realization and interpretation.

The artist's own textile collection provides the base for Mossy Rose, a work commissioned by Lakeside Arts Centre in Nottingham for the exhibition, 'Evolution of Stitch'. Using found fragments of textile sources collaged together by the artist, Maier creates four panels, highlighting different textile details as the pencil begins to playfully mimic various methodologies of weave and stitch, while creating a frame within itself.

The idea of 'going back to go forwards' is a constant theme in Maier's work, like the pen retracing its step, or a thread looping back to form a stitch, where the needle marks a new point that is held connected by a thread to the past. Patterns of stitch, woven thread, handmade mark and pixel become equivalent means towards an intense 
visual experience. Gender references of increasingly subtlety vie with notions of craft in a digital age, and conceptual and mechanical repetition.

The stitch reveals it's meaning through the creation of the mark: in this slippage between mark, stitch, word and meaning, you may wish to search for the nineteen embroidery terms hidden in this text...

\section{Figure 6}

\section{References}

Maier, D. (2005), Have Lunch Downtown, lace wall installation, 20ft $\times 8 \mathrm{ft} \times 1$ in,

London Printworks Trust, London.

(2007), Four Glory Holes, pencil on mylar, $152.5 \times 152.5 \mathrm{~cm}$, Unpicked and

Dismantled, UK exhibition as part of Kaunas Art Biennial: TEXTILE 07, National

Museum of M.K. Ciurlionis, Kaunas, Lithuania.

(2010), Harlequine Slit, $175 \times 75 \mathrm{~cm}$, Closely Held Secrets exhibition, Bonington

Gallery, Nottingham.

(2011), Mossy Rose, $125 \times 125 \mathrm{~cm}$, Evolution of Stitch exhibition, Lakeside Arts

Gallery, Nottingham.

(2013), Pussy Willow, pencil on mylar, 400×110cm, Topographies of the

Obsolete: Vociferous Void, British Ceramics Biennale, Spode Factory, Stoke on

Trent.

Comment [K3]: Please provide the date and Month. When you do this please follow the following format exactly, including connecting punctuation: (2007), Four Glory Holes, pencil on mylar,

$152.5 \times 152.5 \mathrm{~cm}$, Unpicked and Dismantled, UK exhibition as part of Kaunas Art Biennial: TEXTILE 07, National Museum of M.K. Ciurlionis, Kaunas, Lithuania, date Month.

Comment [K4]: Please provide the date and Month. When you do this please follow the following format exactly, including connecting punctuation: (2010), Harlequine Slit, $175 \times 75 \mathrm{~cm}$, Closely Held Secrets exhibition, Bonington Gallery, Nottingham, date Month.

Comment [K5]: Please provide the date and Month. When you do this please follow the following format exactly, including connecting punctuation: (2011), Mossy Rose, $125 \times 125 \mathrm{~cm}$, Evolution of Stitch exhibition, Lakeside Arts Gallery, Nottingham, date Month.

Comment [K6]: Please provide the date and Month. When you do this please follow the following format exactly, including connecting punctuation: __ (2013), Pussy Willow, pencil on mylar, $400 \times 110 \mathrm{~cm}$ Topographies of the Obsolete: Vociferous Void, British Ceramics Biennale, Spode Factory, Stoke on Trent, date Month. 
(2014), Stitch and Peacock, solo exhibition, The Collection Museum and Usher

Gallery, Lincoln.

(2015), Grafting Propriety: From Stitch to the Drawn Line, June, London:

Black Dog Publishing.

\section{List of Figures}

Figure 1: Nest (2005) - photograph by Andrew Weekes @Danica Maier.

Figure 2a: Skein (2005) - photograph by Andrew Weekes @Danica Maier.

Figure 2b: Flock (2005) - photograph by Andrew Weekes @Danica Maier.

Figure 2c: Happy Hunting Ground: Stag detail (2005) - photograph by Andrew Weekes CDanica Maier.

Figure 3: Heirloom (2005) - photograph by Andrew Weekes @Danica Maier.

Figure 4: Pussy Willow (2013) - photograph by David Rowan CDanica Maier.

Figure 5: Four Glory Holes (2007) - photograph by Gerard Williams @Danica

Maier.

Figure 6: Harlequin Slit (2010) - photograph and (C Danica Maier.

\section{Contributor details}

Lucy Renton M.A. (RCA) studied Fine Art at St Martin's School of Art, and Royal

College of Art in London in the 1980s. Since then she has worked as an artist, curator and in a variety of roles in higher education. She is currently Associate Professor in 
the Faculty of Art Design \& Architecture at Kingston University London, and studying for a Professional Doctorate in Fine Art at the University of East London.

Contact:

E-mail: 1.renton@kingston.ac.uk

\section{Artist's biography}

Danica Maier is an artist interested in site-specific installations and events to explore ideas of expectations of site, traditional values, 'women's work' and labour. She completed an MFA in painting at University of Delaware before receiving an M.A. in Textiles from Goldsmiths. Maier has exhibited and curated exhibitions nationally and internationally including co-curated and exhibited in a major exhibition of the work of British-based artists 'Unpicked and Dismantled', a part of the Kaunas Art Biennale. Maier has participated in numerous residency programmes including Braziers International Artist Workshop in the United Kingdom, was artist in residence at the Fundación Migliorisi in Asuncion, Paraguay, and did the apprenticeship at the Fabric Workshop and Museum in Philadelphia. She is currently working as a Senior Lecturer in Fine Art at Nottingham Trent University and is the Coordinator of the Summer Lodge.

Web address: http://www.danicamaier.com 